SHORT REPORT

\title{
Baby walkers: paediatricians' knowledge, attitudes, and health promotion
}

\author{
K Rhodes, D Kendrick, J Collier
}

Arch Dis Child 2003;88:1084-1085

Paediatricians were surveyed about baby walker knowledge, attitudes, and practice. Advising about walkers was associated with working in community paediatrics, treating walker related injuries, knowledge about walkers, and positive attitudes towards walker health promotion. Greater knowledge about walkers was associated with more negative attitudes to walkers. Educating paediatricians and parents about the risks of, and alternatives to using walkers is important.

B aby walkers are used by approximately $50 \%$ of infants in the British Isles. ${ }^{1}$ They do not aid walking ${ }^{2}$ but do pose risks to babies as a result of injury. ${ }^{3}$ The American Academy of Pediatrics recommends banning their manufacture and sale. ${ }^{4}$ Until such time that baby walkers are banned in the UK, health professionals will need to rely on parental education to reduce their use. To do this they need knowledge about walkers, a belief that such education will be effective, and that they are appropriate people to undertake this education. This paper reports a survey of paediatricians' knowledge, attitudes, and practices with respect to walker use.

\section{METHODS}

We developed a questionnaire covering paediatric experience, advice regarding walker use, attitudes towards walkers, and knowledge of walker use and walker related injuries. All consultant and community paediatricians working within the UK in the Royal College of Paediatricians and Child Health handbook (1999-2000) comprised the sampling frame. A total of 180 consultant and 150 community paediatricians were randomly selected and sent the questionnaire in October 2001. Non-responders were sent one reminder after three weeks. Data were double entered into and analysed using SPSS version 11.0. Scales were developed for attitudes towards walkers and towards walker health promotion by summing responses to attitudinal questions (as indicated in table 1) and dividing by the number of questions answered. The scoring was reversed on questions making a positive statement about walkers, so that a high score indicated a more positive attitude towards walkers or walker health promotion. The minimum possible score was 1 and the maximum 5. Summing the correct responses to each of the seven knowledge questions created a knowledge score. Logistic regression was used to determine the factors associated with giving advice about baby walkers, and linear regression for factors associated with attitudes towards walkers and walker health promotion.

\section{RESULTS}

The response rate was $73 \%$ (222/306). Responders had worked as consultant or community paediatricians for a mean of 10.9 (SD 6.7) years. Half (56\%) were community paediatricians, $12 \%$ were general paediatricians, and $12 \%$ were neonatologists. Half (52.5\%) had cared for a child following a walker injury, but only $27 \%$ did so more than once a year. Most (90\%) were parents, of whom 36\% used a walker with their children. Three quarters (74\%) offered advice about walkers, with $74 \%$ always or often advising against their use. Most (89\%) did not have any resources for discussing walkers with parents. None of the paediatricians recommended stationary walkers (exersaucers) as an alternative to a walker. Only one third (34\%) thought the advice they gave parents was effective.

Table 1 shows attitudes towards walkers and walker health promotion. The scale for attitudes towards walkers $(\alpha=0.73)$ ranged from 1 to 4 , with a mean of 2.3 (SD 0.59). The scale for attitudes towards walker health promotion $(\alpha=0.81)$ ranged from 1.25 to 5 , with a mean of 3.4 (SD 0.73). The knowledge score was positively skewed (range 0-6, median 2, interquartile range $0-3)$. Community paediatricians $(b=-0.211,95 \%$ CI -0.370 to $-0.052, p=0.01)$, those with higher knowledge scores $(b=-0.077,95 \%$ CI -0.123 to $-0.030, p=0.001$ ), and those seeing children with a walker injury at least once a year $(b=-0.350,95 \% \mathrm{CI}-0.521$ to $-0.178, \mathrm{p}<0.001$ ) had more negative attitudes towards walkers. Those who had used a walker had more positive attitudes towards walkers ( $b=0.328,95 \%$ CI 0.175 to 0.481 , $\mathrm{p}<0.001)$. Paediatricians with positive attitudes towards walkers had more negative attitudes towards walker health promotion $(b=-0.89,95 \%$ CI -1.01 to $-0.76, p<0.001$, adjusted $\mathrm{R}^{2}=0.49$ ). Table 2 shows that advising about walkers was associated with being a community paediatrician, having greater knowledge of walkers and walker related injury, and having a more positive attitude towards walker health promotion. There was some evidence that those seeing infants with walker related injuries were more likely to give advice, and those whose children had experienced a walker injury were less likely to give advice.

\section{DISCUSSION}

A Europe wide ban on the manufacture and sale of walkers is most likely to reduce injuries associated with their use in the UK. ${ }^{5}$ Education to reduce walker use is important prior to and after legislation as walkers will remain in circulation in the population for some time. ${ }^{5}$ Paediatricians as well as health visitors, midwives, and general practitioners all have a role to play in such education.

Considering alternatives to walkers is likely to be an important part of parental education. Stationary walkers are popular with parents in the USA, ${ }^{6}$ and are likely to have a lower risk of injury while still fulfilling many of the same functions of a mobile walker. However, none of the paediatricians in our survey mentioned these as a possible alternative. The gaps in knowledge about walker related injury also suggest that further education of paediatricians would be helpful. As greater knowledge was associated with more negative attitudes and advising about walkers more frequently, our results 
Table 1 Paediatricians' attitudes towards walkers and walker health promotion (\%)

\begin{tabular}{|c|c|c|c|c|c|}
\hline Question & $\begin{array}{l}\text { Strongly } \\
\text { agree } \\
\text { (score = 1) }\end{array}$ & $\begin{array}{l}\text { Agree } \\
\text { (score = 2) }\end{array}$ & $\begin{array}{l}\text { Not sure } \\
\text { (score = 3) }\end{array}$ & $\begin{array}{l}\text { Disagree } \\
(\text { score = 4) }\end{array}$ & $\begin{array}{l}\text { Strongly } \\
\text { disagree } \\
\text { (score = 5) }\end{array}$ \\
\hline \multicolumn{6}{|l|}{ Paediatricians' attitudes towards walkers } \\
\hline $\begin{array}{l}\text { Baby walkers can be associated with developmental delay in chilaren " } \\
\text { The benefits of baby walkers outweigh the risks }{ }^{*}[4]\end{array}$ & $2(0.9)$ & $18(8.3)$ & $29(13.3)$ & $86(39.4)$ & $83(38.1)$ \\
\hline Baby walkers give babies mobility when they are not ready for it* [6] & $40(18.5)$ & $117(54.2)$ & $28(13.0)$ & $29(13.40)$ & $2(0.9)$ \\
\hline Other equipment could provide just as much enjoyment as baby walkers* [6] & $52(24.1)$ & $128(59.3)$ & $26(12.0)$ & $10(4.6)$ & $0(0)$ \\
\hline Injuries in baby walkers occur rarely* [7] & $5(2.3)$ & $44(20.5)$ & $34(15.8)$ & $95(44.2)$ & $37(17.2)$ \\
\hline Parents are more likely to leave their child unsupervised if they are in a walker* [4] & $29(13.3)$ & $127(58.3)$ & $32(14.7)$ & $30(13.8)$ & $0(0)$ \\
\hline Parents who use walkers with their children fail to recognise the dangers* [6] & $36(16.7)$ & $124(57.4)$ & $28(13.0)$ & $27(12.5)$ & $1(0.5)$ \\
\hline \multicolumn{6}{|l|}{ Paediatricians' attitudes towards walker health promotion } \\
\hline $\begin{array}{l}\text { Parents do not get consistent advice on baby walkers from health } \\
\text { professionals [5] }\end{array}$ & $24(11.1)$ & $129(59.4)$ & $48(22.1)$ & $14(6.5)$ & $2(0.9)$ \\
\hline Paediatricians should advise parents not to use baby walkers† [5] & $38(17.5)$ & $116(53.5)$ & $36(16.6)$ & $22(10.1)$ & $5(2.3)$ \\
\hline Other health professionals have more responsibility to advise on baby walkers [7] & $26(12.1)$ & $112(52.1)$ & $22(10.2)$ & $51(23.7)$ & $4(1.9)$ \\
\hline Injury prevention specialists over emphasise the dangers of baby walkers $†[6]$ & $0(0)$ & $32(14.8)$ & $58(26.9)$ & $103(47.7)$ & $23(10.6)$ \\
\hline $\begin{array}{l}\text { In paediatrics, other safety issues are more important than baby walker } \\
\text { injuriest [10] }\end{array}$ & $8(3.8)$ & $111(52.4)$ & $29(13.7)$ & $59(27.8)$ & $5(2.4)$ \\
\hline $\begin{array}{l}\text { The professional bodies in paediatrics should recommend that parents do not } \\
\text { use walkerst [4] }\end{array}$ & $21(9.6)$ & $117(53.7)$ & $51(23.4)$ & $26(11.9)$ & $3(1.4)$ \\
\hline Professional bodies should campaign to ban baby walkers $†[6]$ & $13(6.0)$ & 43 (19.9) & $61(28.2)$ & $94(43.5)$ & $5(2.3)$ \\
\hline $\begin{array}{l}\text { Professional bodies should advise industry about designing baby walkers to make } \\
\text { them safer [5] }\end{array}$ & $17(7.8)$ & $116(53.5)$ & $39(18.0)$ & $41(18.9)$ & $4(1.8)$ \\
\hline $\begin{array}{l}\text { Educating parents about the risks of baby walkers is likely to be more beneficial } \\
\text { than trying to ban their sale [4] }\end{array}$ & $21(9.7)$ & $139(64.4)$ & $25(11.6)$ & 28 (13.0) & $3(1.4)$ \\
\hline $\begin{array}{l}\text { Parents can access enough information about the risks and benefits of baby } \\
\text { walkers† [5] }\end{array}$ & $2(0.9)$ & $16(7.4)$ & $59(27.3)$ & $123(56.9)$ & $16(7.4)$ \\
\hline
\end{tabular}

[missing values]

*Included in paediatricians' attitude towards walkers scale.

tIncluded in paediatricians' attitudes towards walker health promotion scale.

Table 2 Factors associated with paediatricians ever giving advice about baby walkers

\begin{tabular}{|c|c|c|}
\hline Characteristic & Unadjusted odds ratio $(95 \% \mathrm{Cl})$ & $\begin{array}{l}\text { Odds ratio }(95 \% \mathrm{Cl}) \text { adjusted } \\
\text { for other variables in model }\end{array}$ \\
\hline Community paediatrician & $5.27(2.62$ to 10.61$) ; p<0.001$ & 4.72 (2.00 to 11.16$) ; p<0.001$ \\
\hline Years as a paediatrician & $0.97(0.93$ to 1.02$) ; p=0.23$ & \\
\hline \multicolumn{3}{|l|}{ Number of infants seen per week } \\
\hline 5 or less & 1.00 & \\
\hline $6-10$ & $0.85(0.40$ to 1.82$) ; p=0.68$ & \\
\hline $11-15$ & $0.62(0.25$ to 1.54$) ; p=0.31$ & \\
\hline $16-20$ & $0.57(0.17$ to 1.86$) ; p=0.35$ & \\
\hline$>20$ & $0.68(0.21$ to 2.17$) ; p=0.52$ & \\
\hline Has own children & $1.20(0.44$ to 3.27$) ; p=0.72$ & \\
\hline Used walker with own children & $0.41(0.21$ to 0.77$) ; p=0.006$ & \\
\hline Sees children with baby walker injuries at least once a year & $4.96(1.87$ to 13.16$) ; p=0.001$ & $3.37(0.96$ to 11.87$) ; p=0.058$ \\
\hline Own child had accident in walker & $0.58(0.16$ to 2.06$) ; p=0.40$ & $0.13(0.02$ to 1.14$) ; p=0.066$ \\
\hline Knowledge of walkers and walker related injuries & $1.37(1.11$ to 1.70$) ; p=0.004$ & $1.39(1.04$ to 1.86$) ; p=0.024$ \\
\hline Attitude towards baby walkers & $5.12(2.93$ to 8.96$) ; p<0.001$ & \\
\hline Attitude towards walker health promotion & $0.12(0.06$ to 0.24$) ; \mathrm{p}<0.001$ & 4.26 (2.09 to 8.68$) ; p<0.001$ \\
\hline
\end{tabular}

suggest that education might have the potential to impact on practice. Further work is required to test this hypothesis.

Despite a good response rate, paediatricians least knowledgeable and most positive towards walkers are probably least likely to have responded. Our results may therefore overestimate negative attitudes and knowledge about walkers among the general population of paediatricians, and underestimate the need for educating paediatricians about walkers and their associated risks.

\section{Authors' affiliations}

K Rhodes, University of Nottingham Medical School, Queen's Medical Centre, Clifton Boulevard, Nottingham, UK

D Kendrick, Division of General Practice, Floor 13, Tower Building, University Park, Nottingham, UK

J Collier, Academic Division of Child Health, University Hospital, Nottingham, UK
Correspondence to: Dr D Kendrick, Division of General Practice, Floor 13, Tower Building, University Park, Nottingham NG7 2RD, UK; denise.kendrick@nottingham.ac.uk

Accepted 12 March 2003

\section{REFERENCES}

1 Kendrick D, Marsh P. Babywalkers: prevalence of use and relationship with other safety practices. Inj Prev 1998:4:295-8.

2 Siegel AC, Burton RV. Effects of baby walkers on motor and mental development in human infants. Dev Behav Pediatr 1999;20:355-61

3 Stoffman JM, Bass MJ, Fox AM. Head injuries related to the use of baby walkers. Cmai 1984;131:573-5.

4 American Academy of Pediatrics. Policy statement-injuries associated with infant walkers. AAP, 2001.

5 Morrison CD, Stanwick RS, Tenenbein M. Infant walker injuries persist in Canada after sales have ceased. Pediatr Emerg Care 1996;12:180-2.

6 Dilillo D, Damashek A, Peterson L. Maternal use of baby walkers with young children: recent trends and possible alternatives. Inj Prev 2001;7:223-7. 